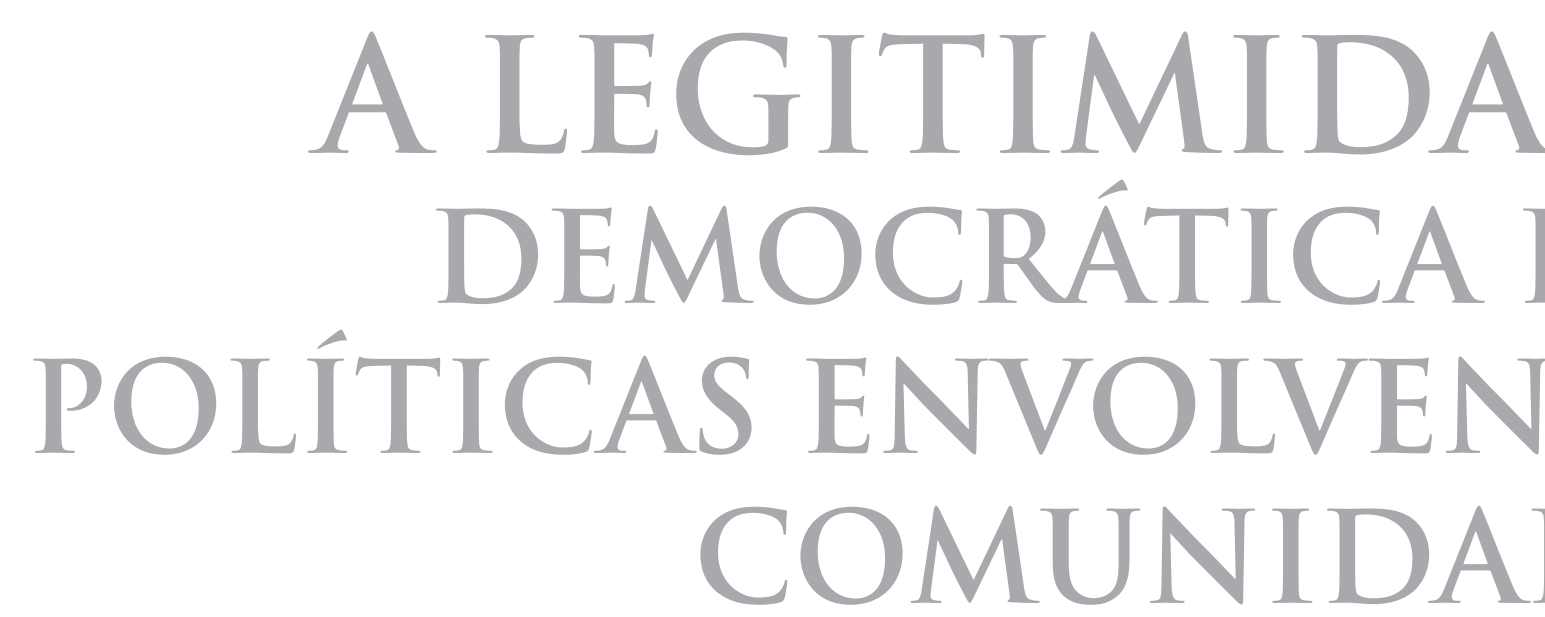

TRADICIONAIS: OS DESAF DO SISTEMA POLÍT] EM UMA SOCIED, MULTICULTU 


\section{A LEGITIMIDADE DEMOCRÁTICA DAS POLIITICAS ENVOLVENDO COMUNIDADES TRADICIONAIS: OS DESAFIOS DO SISTEMA POLIITICO TRADICIONAL EM UMA SOCIEDADE MULTICULTURAL}

NATHALIA MARIEL FERREIRA DE SOUZA PEREIRA

UNIVERSIDADE CATÓLICA DE BRASílIA

JULIO CESAR DE AGUIAR

UNIVERSIDADE CATÓLICA DE BRASílIA 


\title{
A LEGITIMIDADE DEMOCRÁTICA DAS POLÍTICAS ENVOL- VENDO COMUNIDADES TRADICIONAIS: OS DESAFIOS DO SISTEMA POLÍTICO TRADICIONAL EM UMA SOCIEDADE MULTICULTURAL
}

\author{
Resumo \\ O presente trabalho visa, através de um estudo teórico interpreta- \\ tivo, discutir a falta de legitimidade e validação de ações políticas \\ voltadas às minorias tradicionais, no caso comunidades indíge- \\ nas, em razão do vácuo de representatividade e na inconsequen- \\ te homogeneização realizada entre a sociedade tradicional e tais \\ grupos. O debate se dará com base na liberdade comunicativa de \\ Habermas como instrumento de gozo dos direitos políticos fun- \\ damentais e do princípio do discurso como prisma de validação \\ de normas em uma sociedade globalizada e pluralista. Utilizare- \\ mos de exemplo a situação da Estrada de Ferro Carajás no sul do \\ Pará e o diálogo inefetivo entre Estado e comunidade indígena. \\ Palavras-chave: Democracia, legitimidade, indígenas, multicultu- \\ ralismo, liberdade comunicativa.
}

\section{THE DEMOCRATIC LEGITIMACY OF POLICIES INVOLVING TRADITIONAL COMMUNITIES: THE CHALLENGES OF THE TRADITIONAL POLITICAL SYSTEM IN A MULTICULTURAL SOCIETY}

\begin{abstract}
This manuscript intends, by means of an interpretative theoretical study, to discuss the lack of legitimacy and validation of political actions aimed at traditional minorities, in the case of indigenous communities, due to the vacuum of representativeness and the inconsequential homogenization between traditional society and such groups. The debate will be based on the communicative freedom of Habermas as an instrument for the enjoyment of fundamental political rights and the principle of discourse as a prism for the validation of norms in a globalized and pluralistic society. We will use the example of the situation of the Carajás Railroad in southern Pará and the ineffective dialogue between the State and the indigenous community.
\end{abstract}

Keywords: Democracy, legitimacy, indigenous, multiculturalism, communicative freedom. 


\section{LA LEGITIMIDAD DEMOCRÁTICA DE LAS POLÍTICAS EN COMUNIDADES TRADICIONALES: LOS DESAFÍOS DEL SISTEMA POLÍTICO TRADICIONAL EN UNA SOCIEDAD MULTICULTURAL}

\section{Resumen}

El presente artículo busca, a través de un estudio teórico interpretativo, discutir la falta de legitimidad y de validación de acciones políticas dirigidas a minorías tradicionales. En el caso de las comunidades indígenas, a razón del vacío de representatividad y en la inconsecuente homogeneización realizada entre la sociedad tradicional y tales grupos. El debate se da con base en la libertad comunicativa de Habermas como instrumento de goce de los derechos políticos fundamentales y del principio del discurso como prisma de validación de normas en una sociedad globalizada y pluralista. Utilizaremos de ejemplo la situación de la Estrada de Ferro Carajás en el sur de Pará y el dialogo inoperante entre el Estado y la comunidad indígena.

Palabras clave: Democracia, legitimidad, indígenas, multiculturalismo, libertad comunicativa.

Nathalia Mariel Ferreira de Souza Pereira

nathaliamariel@,hotmail.com 


\section{INTRODUÇÃO}

O sistema democrático abrange tradicionalmente a vontade da maioria e valida de tal forma e método a tomada de decisões políticas, que abrangem tanto decisões administrativas quanto legislativas. Todavia, existem grupos que ficam de fora das chamadas maiorias nacionais, e por serem grupos pequenos acabam sendo abrangidos pela representatividade do grupo em vantagem numérica, ficando sem voz e sem possibilidade de efetivo exercício de seus direitos políticos.

Segundo Habermas, só há democracia e liberdade comunicativa quando todos os cidadãos têm possibilidade de participarem das tomadas de decisões. Com base nessa premissa, em uma sociedade onde existem grupos sistematicamente excluídos de tal participação, é possível concluir que eventuais ações políticas não serão válidas para tais grupos.

Nesse contexto Habermas já chamava atenção para o fato de que a compreensão da democracia implica mudanças no modo de entender a política, uma vez que, para que uma decisão administrativa seja de fato legítima, ela deve estar embasada no consenso livre e explícito de todos os cidadãos de uma nação (Habermas 2005:22).

Cabe ressaltar que não se trata tão somente de participação política meramente formal, porém, da uma participação efetiva, em que sobressaem os elementos necessários para desenvolvimento concreto da comunicação entre os sujeitos, que pressupõem uma linguagem apta a promovê-la, pressupostos estes que podem ser apontados como indispensáveis em uma análise antropológica da participação política envolvendo comunidades tradicionais.

Temos ainda o princípio do discurso e seus subprincípios, por alguns não considerado como teoria própria e sim como auxiliar da ação comunicativa (Siebeneichler 2010), que buscam justamente validar normas em um contexto democrático efetivo, o que será trabalhado no presente artigo de forma a explicar o porquê do vácuo de representatividade existir em nosso sistema, considerando que vivemos em uma sociedade globalizada, não apenas economicamente, mas também culturalmente, abarcando ordens jurídicas distintas que reclamam direitos distintos e atenção diferenciada (Habermas 1998:102104).

Partindo da premissa da existência de sistemas sociais, adotamos a concepção de que tais sistemas se comunicam e se interligam e em temática de comunidades tradicionais, compostas de sujeitos oriundos de traços culturais muito singulares, há uma necessária preocupação com a forma desse discurso, para que os sujeitos possam se entender e se ouvir e assim preencher as lacunas de soberania que surgem em uma sociedade globalizada.

Conforme trabalhado por Habermas, a globalização afeta não apenas aspectos econômicos e jurídicos, mas essencialmente a própria administração pública, meio pelo qual uma sociedade se organiza e estabelece uma ordem democrática que eventualmente terá um problema de legitimidade (Habermas 1998). 
No caso brasileiro, existem alguns exemplos que demonstram na prática a problemática da representatividade de minorias étnicas, como é o caso dos indígenas Gavião, que será trabalhado no artigo, que em razão da ausência de consulta e oitiva das comunidades para a duplicação da Estrada de Ferro Carajás, projeto inserido no Grande Carajás de exercício da Vale S.A, vem sofrendo uma série de dificuldades.

A conclusão a que se quer chegar é que os sistemas que integram a sociedade devem se comunicar através de instrumentos de democracia deliberativa próprios para comunidades tradicionais, aproveitando-se assim o potencial emancipatório presente na esfera pública e na sociedade civil, de maneira equilibrada, conferindo criticamente efetiva legitimidade e validade para a tomada de decisões na seara política voltado às minorias.

Esse estudo é feito através da consulta bibliográfica e da análise do marco teórico do pluralismo jurídico, usado para adequar as noções dos institutos tradicionais que serão aqui abordados.

\section{DEMOCRACIA DO PONTO DE VIS- TA TRADICIONAL}

A teoria política clássica define a democracia como "o arranque institucional para se chegar a decisões políticas que realiza o bem comum fazendo o próprio povo decidir as questões através da eleição de indivíduos que devem reunir-se para realizar a vontade desse povo" (Schumpeter 1984). Segundo essa visão, bastante tradicional, nosso sistema democrático é um sistema de maiorias que funciona muito bem em razão de ser um sistema que confere vOz, em tese, aos anseios políticos da sociedade.

Ainda segundo a visão clássica, o sistema democrático comporta duas formas típicas por meio das quais a sociedade civil constitui a representatividade política, a forma direta e a indireta, sendo esta última o modelo utilizado mais fortemente. $\mathrm{Na}$ representatividade indireta, predominante no sistema político adotado no Brasil, a população elege seus representantes os quais, na prática, são os que têm poder decisório e voz.

"O sistema democrático comporta a vontade da maioria, porém não deve desconsiderar o espaço social de todos os grupos de compõe a sociedade: A ideia de democracia não se limita ao governo da maioria, mas abrange o espaço em que se comportam as diversas visões existentes em uma comunidade política, ainda que uma delas prevaleça. Um espaço que permite a diversidade tem como pressuposto - e também como referencial comum - a igualdade de condições para participar da construção desse lugar político múltiplo” (Martins \& Mituzani 2011)

Kelsen trabalha a ideia de que no sistema democrático não haveria apenas a voz da maioria e sim um debate e composição entre essa maioria e a minoria, sendo que quanto mais forte as minorias, maior o compromisso político e o seu comprometimento (Kelsen 2010).

Como forma de conferir essa composição há na Constituição Federal, pre- 
visão de meios de representatividade semi-direta que por excelência são a iniciativa legislativa, o plebiscito e o referendo.

Sartori define que a democracia representativa tem base vertical e vem se desenvolvendo nos últimos anos de maneira sólida, enquanto a democracia direta ou semidireta tem base horizontal e, apesar de sua sustentação histórica ser mais densa, seu desenvolvimento é lento e sem grandes incentivos (Sartori 1994).

Não sendo tais meios suficientes e considerando que a representatividade indireta por excelência, confere voz às maiorias, temos grupos de minorias nacionais que ficam sem espaço para suas reivindicações e são obrigados por vezes a aceitar políticas que são contrárias ou que afetam seus interesses sem qualquer possibilidade de debate ou qualquer discussão mais efetiva.

Por vezes, as eventuais insatisfações de grupos de minorias são levadas para resolução junto ao Judiciário, justamente por não possuir espaço de debate nas esferas do Poder Executivo e Legislativo. Temos então um paradoxo: um sistema que deveria representar a sociedade e promover a participação política, acaba por excluir a voz de diversos grupos de minorias que quase sempre, são sujeitos de direitos e reivindicações dispostas no próprio texto Constitucional

Esse modelo tradicional democrático de representação política, tanto indireta como direta, foi idealizado como forma de rebate à sistemas de opressão e de ausência de consenso, não se adequando, porém, a uma sociedade que cada vez mais vê se dissolverem as fronteiras e em cujo seio, a cada dia, emergem grupos e mais grupos de sujeitos, sejam eles tradicionais (objeto do presente artigo) ou surgidas de direitos e violações sistemáticas de direitos humanos, a exemplo dos refugiados.

Cumpre aqui incluir uma discussão sobre a problemática de defesa dos direitos humanos de minorias. Após a Segunda Guerra Mundial, cenário de diversas violações sistemáticas de garantias fundamentais, surge com maior intensidade a preocupação com a positivação e defesa dos direitos humanos, que a priori foi uma preocupação legítima.

Porém, colocou-se no mesmo contexto de defesa direitos que mereciam atenção diferenciada em decorrência de suas peculiaridades, razão pela qual há a busca do chamado multiculturalismo emancipatório, fugindo assim da homogeneização que acaba enfraquecendo a defesa das garantias desses grupos.

Para Santos "enquanto forem concebidos como direitos humanos universais, os direitos humanos terão a operar como localismo globalizado e, portanto, como forma de globalização hegemônica" (Santos 2010:438). A relação entre competência global e legitimidade local é a pré-condição de uma política contra-hegemônica de direitos humanos, que exige sua transformação à luz do pluralismo.

São os direitos humanos uma construção cultural de cada povo, e nessa construção e seus fundamentos de- 
vemos procurar os elementos necessários para legitimar suas bases, pois, uma pretensa fundamentação universal não tem tido eficácia por não refletir esta realidade, tendo em vista que são as ideias e teorias que devem se adaptar aos fatos e traços culturais (Silva 2008).

Vê-se que o problema é similar à utilização do sistema democrático, que coloca em uma mesma massa todo o grupo de minorias e maiorias em um discurso comum, como vOz de todos os diferentes grupos que compõe a nossa sociedade, sendo que esse discurso comum não traduz um consenso construído após um debate e sim a ignorância dos eventuais argumentos e contrapontos que poderiam ser trazidos por grupos minoritários, enriquecendo eventualmente o discurso.

Em razão de tais problemáticas, a tomada de decisões políticas apesar de ser conferida em um contexto democrático, não é legítima nem válida para utilização. Habermas, em suas discussões sobre teoria da ação comunicativa e democracia, traz para debate o uso da linguagem e a importância dos fluxos comunicacionais para a construção de um sistema democrático efetivo, bem como para fazer surgir uma forma procedimental de execução de tal sistema democrático através da deliberação, que será discutida nos próximos capítulos.

\section{ORDENS JURÍDICAS DISTINTAS E MULTICULTURALISMO}

Toda essa discussão sobre a legitimidade ou não da tomada de decisões em face de comunidades tradicionais surge como preocupação justamente com a evolução da sociedade, que passa a ter e reconhecer minorias nacionais em maiores grupos, esvaziando o poder da soberania nacional (poder de Estado):

"A globalização do trânsito e da comunicação, da produção econômica e de seu financiamento, da transferência de tecnologia e poderio bélico, especialmente dos riscos militares e ecológicos, tudo isso nos coloca em face de problemas que não se podem mais resolver nos âmbitos dos Estados nacionais, nem pela via habitual do acordo entre Estados soberanos. Salvo melhor juízo, tudo indica que continuará avançando o esvaziamento da soberania de Estados nacionais, o que fará necessária uma reestruturação e ampliação das capacidades de ação política em um plano supranacional (...) Por isso defendo a opinião de que podemos nos orientar nesse caminho incerto rumo às sociedades pós-nacionais justamente segundo o modelo da forma histórica que estamos prestes a superar". (Habermas 2002:129).

Com relação ao termo "minorias nacionais" cabe uma maior explicação sobre suas origens, considerando seu uso inicialmente por Pierre-Caps em 2004, ao realizar o estudo do surgimento da categoria de minoria em um contexto europeu em que se definia o princípio das nacionalidades, como meio de identificar a Nação e diferenciá-la do Estado (Martins \& Mituzani 2011).

Em um contexto de reconhecimento do que seria Estado, surge o conceito dos grupos minoritários que compunham um Estado e que não se iden- 
tificavam com os demais elementos comuns daquela sociedade:

"Mas ao mesmo tempo em que a condição de minoria era abafada por elementos circunstanciais, a inegável presença de grupos minoritários faz emergir a problemática das minorias. Ocultá-las, não reconhecê-las ou desconsiderá-las como uma questão a ser enfrentada pelos Estados nacionais confirmavam a existência do que seria posteriormente denominada "minorias nacionais" (...). Era inadequado pensar em povos associados a elementos identitários diversos daqueles eleitos pelos Estados nacionais em formação e afirmação" (Martins \& Mituzani 2011:332).

Conforme o preâmbulo da Declaração Universal sobre a Diversidade Cultural da ONU, cultura pode ser definida como o conjunto dos traços distintivos espirituais e materiais, intelectuais e afetivos que caracterizam uma sociedade ou um grupo social e que abrange, além das artes e das letras, os modos de vida, as maneiras de viver juntos, os sistemas de valores, as tradições e as crenças. ${ }^{1}$

Com a existência de diversas ordens jurídicas paralelas com poder e soberania próprios que não possuem espaço em um sistema democrático tradicional, mas que necessitam de debate e voz, presencia-se uma sociedade política e que em razão da globalização torna-se ou já se constitui desde sua gênese, uma sociedade culturalmente diversificada, com um movimento de automática incorporação dessas minorias nacionais, ao invés de compreensão e diálogo.
A sociedade globalizada é composta de pessoas diferenciadas que trazem em suas individualidades experiências e traços culturais diferenciados. Compor tudo isso em um único discurso acaba anulando esses traços diferenciadores e não acarreta uma sociedade efetivamente democrática, uma vez que o sistema leva em consideração as massas acarretando uma participação sem maiores reflexões sobre suas reais consequências, comum nas sociedades contemporâneas. (Gomes 2010).

Habermas trabalha a ideia de dinâmica de mundo globalizado e limitações que residem justamente na dificuldade de legitimar a política democrática como forma de integração social em uma sociedade cada vez mais interdependente e interconectada.

A globalização como fenômeno de diversas frentes vem fazendo o direito e todo o sistema político tradicional ser repensado e trabalhado agora em uma concepção transnacional:

"Globalisation is already having, and will continue to have, a major impact on the landscape of specialised legal fields. But this is happening in varied ways. Some clear trends are already apparent. First, greater emphasis is being placed on established transnational fields, such as public international law, regional law, environmental law, international trade and finance(...)As was noted above, since about 1990 there has seen a spate of "rethinkings" in several transnational fields." (Twining 2009). ${ }^{2}$

A existência de grupos minoritários, cada vez mais comuns em razão da globalização e quebra das barreiras nacionais, acarretam o surgimento de or- 
dens cultural e juridicamente distintas, que reclamam direitos diferenciados e espaço para que uma democracia efetiva, construída através de um padrão procedimental baseado na linguagem, possa funcionar.

Esse novo Estado surgido na era da globalização, conceituado como sociedade pluralista, constrói e baseia a preocupação de novos procedimentos aptos a validar ações políticas voltadas aos grupos minoritários.

\subsection{Multiculturalismo emancipatório}

Conforme debatido anteriormente, a tendência de universalização dos direitos humanos em uma estrutura hegemônica que ocorreu fortemente após a Segunda Guerra Mundial acabou enfraquecendo a luta dos direitos humanos de minorias, os quais, por possuírem traços distintos, mereciam (e merecem) atenção distinta.

Existem questionamentos acerca do poder emancipatório que os direitos humanos supostamente possuiriam na luta em prol dos grupos minoritários, mas que, na verdade, em razão dessa ocidentalização de direitos, perde força na realidade do dia a dia, propondo-se, então, a ideia de uma política de direitos humanos que nada mais é que uma política cultural justamente por traduzir uma política de diferenças (Santos 1997).

Uma das tensões apontadas por Santos diz respeito ao conflito dialético existente entre a sociedade civil e o Estado, pois as leis que regulamentam a convivência em sociedade são consideradas legítimas tão somente pelo respeito ao processo democrático (Santos 1997). Ocorre que tal processo democrático deve se basear em uma política de direitos humanos que trate das diferenças, pois só assim permitir-se-ia o caráter emancipatório e de igualdade material entre os grupos culturalmente soberanos ${ }^{3}$ que compõe um Estado Nação.

A sociedade globalizada, entendida não apenas em seu aspecto econômico, mas sendo compreendida a partir da totalidade do alcance de sua definição de superação de fronteiras e enfraquecimento do conceito tradicional de soberania estatal, já que um Estado na verdade é composto de várias e soberanas nações, como as comunidades indígenas por exemplo.

Nesse aspecto de soberania, importante destacar que sua conceituação clássica envolve os seguintes aspectos:

"Para que um Estado seja aceito como ente soberano ele depende de quatro elementos essenciais: um território, uma população, um governo que exerça poder sobre este território e a população e o reconhecimento (como Estado) pelos outros Estados-Nações, constituintes da sociedade internacional." (Sobrino 2004).

Em razão do estudo de multiculturalismo emancipatório nos termos do trabalho de Santos, esse conceito de soberania é relativizado, pelo menos em termos culturais, justamente pelo reconhecimento de culturas oriundas de povos que compõe uma ordem jurídica paralela, o que reforça ainda mais a vigência do pluralismo jurídico em nossa sociedade moderna. 
O diálogo com tais comunidades, com seus traços culturais tradicionais de caráter soberano, deve ser travado com considerações efetivas de respeito às diferenças culturais e com base em uma concepção de multiculturalismo, onde tais diferenças se comuniquem mutuamente e permitam o fluxo de informações, para assim garantir os direitos desses grupos:

"O direito das minorias representa, portanto, direitos fundamentais de parcelas da sociedade eleitas como minorias a partir de parâmetros de marginalização histórica. A marginalização desses grupos deu-se por meio de discriminação social, representação política deficiente ou inexistente, subvalorização cultural, omissão - ou mesmo violência das instituições estatais, para citar as principais causas de desprestígio em relação às minorias. $O$ termo, ressalte-se, não está associado a uma minoria quantitativa necessariamente: os grupos minoritários podem ser compostos de parcelas consideráveis da sociedade" (Martins \& Mituzani 2011:335)

Para conseguir alcançar o caráter emancipatório dos direitos humanos das minorias, é importante o estudo do que seria o pluralismo jurídico tão aclamado para a luta das comunidades tradicionais:

'Legal pluralism can be defined as a concept which refers to legal systems, networks or orders co-existing in the same geographical space. Its origins can be traced back to the 1960s' empirical studies of postcolonial societies conducted by legal anthropologists who showed that in colonial and post-colonial societies a great deal of social and conflict resolution took place under traditional norms and processes which were not officially recognised as law and which were sometimes even in conflict with national or state law, usually termed as modern law and imposed by western colonial forces. The beginnings of legal pluralism were thus underlined by the critique of hegemonic ex-colonial forces and of their disregard and contempt for the indigenous law and for local traditions. This line of legal pluralism can be called a post-colonial account of legal pluralism." (Avbelj 2007)

O pluralismo jurídico é assim a existência de ordens jurídicas distintas, nem sempre emitidas pelo Estado, mas que, ainda quando em conflito com aquele, deve ter seu estudo realizado e reconhecido, justamente para alcançar o direito de reconhecimento das comunidades tradicionais:

"Social scientists who tout the concept of legal pluralism emphatically proclaim that law is not limited to official state legal institutions. To the contrary, they insist, law is found in the ordering of social groups of all kinds." (Tamanaha 2008)

Existindo esse direito emitido pelos grupos sociais em uma sociedade juridicamente plural, tem-se que o seu caráter emancipatório é flagrante, diante de seu reconhecimento como válido e como necessário em um diálogo entre comunidade e Estado.

\section{TEORIA DA AÇÃO COMUNICATI- VA DE HABERMAS}

É importante partir da premissa de que o ser humano tem natureza social e subjetiva, e são esses seres humanos que juntos vão compor a sociedade e estabelecer laços políticos. Tal premis- 
sa é utilizada por Habermas para explicar conceitos básicos de democracia, liberdade e discurso, que servem como luva para o entendimento no presente artigo da importância de novos instrumentos aptos a conferir legitimidade democrática para ações políticas envolvendo minorias étnicas.

Assim, sabendo que o ser humano nada mais é do que o resultado de todas as suas experiências culturais, é essencial entender que aprendemos um com os outros e, em um espaço próprio, fornecemos estímulos recíprocos. Consequentemente, em uma sociedade multicultural e de política totalmente secularizada e indiferente a cosmovisões, não é mais possível construir ou manter um Estado sem que se lance mão da ideia do direito e da democracia radical (Habermas 1994).

No clássico "Direito e Democracia", Habermas traz a conceituação de democracia real apenas quando o sistema está ancorado no consenso livre e explícito da totalidade dos cidadãos de uma nação, nação que pela concepção de globalização é composta de várias minorias nacionais, que precisam em diálogo descobrir seu consenso. A ação comunicativa aqui aparece como a forma de agir através da linguagem e do diálogo para efetivar uma sociedade democrática.

É nesse cenário que a liberdade comunicativa desponta como decisiva para o gozo dos direitos políticos fundamentais subjetivos de cada um, bem como para o exercício da autonomia política pública em um contexto democrático.
Habermas busca em sua obra entender e fazer comunicar a esfera política e a esfera privada dos cidadãos. E a ponte para efetivar essa comunicação é o chamado princípio do discurso, que, essencialmente, parte do pressuposto de que uma política adequada à natureza social e subjetiva dos seres humanos tem que ser pensada em termos de uma ordem a ser criada por cidadãos apoiados em um direito e em instituições democráticas, participando de discursos práticos em um determinado espaço público político (Habermas 2005).

Ou seja, esse princípio tem como objetivo justificar a validade e legitimidade das normas, sejam elas de ordem jurídica ou moral, de maneira abstrata e perpassando dois subprincípios distintos e complementares: o princípio moral ou princípio " $U$ " ou ainda princípio da universalização das normas morais, segundo o qual as consequências e efeitos colaterais oriundo das ações devem ser aceitáveis por todos os participantes do discurso; e o princípio da democracia, de acordo com o qual a ordem jurídica só pode ser válida e legítima se puder contar com o consentimento não obstaculizado e juridicamente operacionalizado da sociedade, traduzido na liberdade comunicativa de todos os cidadãos de um Estado (Habermas 2005).

A teoria de Habermas traduz a importância do diálogo efetivo entre os grupos que compõe a sociedade, como forma de validar e legitimar decisões políticas como um todo. O grande problema surge quando, em uma sociedade cosmopolita, esse consenso se torna 
mais difícil para um Estado moderno que ainda mantêm sistemas políticos tradicionais.

No contexto de mundo globalizado, fenômeno este que não deve ser visto somente do ponto econômico, mas também cultural, as barreiras nacionais praticamente somem. Da mesma forma, as barreiras internas também perdem espaço, com o fortalecimento de grupos nacionais - aqui não tratados na forma separatista, mas na diferenciação cultural de grupos tratados tradicionalmente como homogêneos -, restando profundamente afetada a legitimação da administração pública, que nada mais é do que a forma como a sociedade se organiza (Habermas 1998).

É por força dessa natureza multicultural que Habermas aponta a necessidade de a sociedade permanecer "porosa”, ou seja, permeável a novas ideias, conceitos e entendimentos, a fim de manter a capacidade de inclusão de todos na comunidade política, sem a pretensão de uniformidade nacional hegemônica e sim com a ideia de debate, comunicação sem sufocamento das liberdades comunicativas das pessoas que a compõem.

\subsection{O agir comunicativo e a razão discursiva}

Tratou-se até agora da importância da liberdade comunicativa em um Estado multicultural, resultado de um intenso e constante processo de globalização, bem como da necessidade do discurso como ponte na validação e legitimação de normas jurídicas e morais.
O foco da discussão agora passa a ser a forma de manifestação da liberdade comunicativa em um grupo, isto é, a questão de como a linguagem deve ser tratada, a fim de permitir um diálogo social. Nesse ponto temos a teoria do agir comunicativo, que supera as exigências formais de linguagem - quais sejam locutor, interlocutor, língua e entendimento comum, ausência de coerção e intenção mútua de alcance de entendimento -, elementos estes necessários para validade dos instrumentos pesquisados para preenchimento dos vácuos democráticos, e busca trazer elementos ontológicos dos sinais da comunicação.

A linguagem tem dupla função, tanto função interativa como função discursiva ou argumentativa, sendo que, nessa segunda função, ela é apta a conferir força à legitimação do sistema jurídico e político, trazendo estabilidade à sociedade democrática. Em uma sociedade composta de sistemas, a interação entre as camadas se dá através da linguagem, as ações sociais nada mais são do que uma resposta às necessidades individuais de cada ator social (Habermas 1983).

O agir comunicativo nada mais é do que o próprio discurso, legitimador de normas, e não possui apenas um interlocutor, mas vários e em vários tons que se juntam formando uma pluralidade de vozes em uma realidade de intertextualidade, onde muito mais se valoriza a intenção do sujeito e a racionalidade (Jesus 2010).

A racionalidade desse agir comunicativo é oriunda de algumas reservas 
sociais culturais (Habermas 1986), a sociedade tem uma herança e uma tradição cultural trazida pelos indivíduos e que marcam os contornos do seu discurso, sendo uma das muitas variáveis que interferem na comunicação.

Inicia-se aqui alguns elementos casuísticos do trabalho, qual seja, a questão das comunidades indígenas como grupos minoritários, que já entram no canal de comunicação com o restante da sociedade e com a administração públi$\mathrm{ca}$, em desvantagem oriunda tanto de sua representatividade numérica na sociedade como pela carga cultural que é compreendida pela sociedade em geral.

Outro elemento importante à concretização do diálogo é o interesse comum entre as partes, a intenção de se ouvirem e chegarem a um denominador comum, só alcançável através da igualdade de informações e uma língua que não necessariamente seja a mesma, mas que consiga concretizar um conhecimento integral dos diálogos. Esse ponto, em matéria de comunidades tradicionais versus administração pública é muito importante e elemento fundante da busca de instrumentos aptos à efetivar o fluxo comunicacional no caso.

A ideia é que o discurso valide as normas universais, agora não mais de um ponto de vista individual, com base, por exemplo, no imperativo categórico de Kant, mas através da argumentação moral e pela busca do reconhecimento mútuo da validade dos argumentos pelos integrantes de uma discussão, ou seja, sua validação é realizada através da consciência coletiva (Lorenzo 2011).
A lógica de tal mecanismo reside no confronto entre a moral individualista e a moral coletiva, onde a primeira é insuficiente para alcançar soluções efetivas para os conflitos existentes na sociedade, uma vez que gera enormes riscos de ser etnocêntrica e universalmente abstrata (Lorenzo 2011).

No próximo capítulo trataremos mais especificamente dos indígenas, como exemplo de minorias nacionais nesse sistema tradicional democrático. O ponto focal da discussão pode ser resumido na seguinte questão: em relação a grupos de minorias étnicas que não possuem voz em um sistema político de maiorias, como conferir legitimidade às decisões políticas tomadas, uma vez que não houve consenso ou debate?

Pela teoria de Habermas, tais decisões não seriam legítimas, tendo em vista que não houve diálogo ou inserção de tais minorias dentro da sociedade política majoritária. Por outro lado, como garantir, caso haja vontade do Estado em ouvir tais povos, que a linguagem seja uma forma de argumentação efetiva e não meramente uma interação social?

\section{CULTURA E GRUPOS MINORITÁ- RIOS: INDÍGENAS}

A utilização do termo Minorias é um reforço de argumentação em matéria de democracia, justamente para impor a análise de seu estudo na tomada de decisões (Martins e Mituzani 2011) e podem ser definidas como:

"todo grupo social detentor de traços relativamente indeléveis e cujos 
membros não poderiam por esse motivo fundir-se em maioria da população, a orientação sexual são alguns exemplos de traços próprios de um grupo social e que podem isolá-lo. [...] Nem todos esses traços são absolutamente indeléveis, pode-se mudar de língua, de religião, escolher integrar-se ao modo de vida da população dominante, mas a questão é saber se é obrigado a fazê-lo, mais exatamente, se as leis adotadas pela maioria podem coagir ou incitar a isso". (Rigaux 2003:35-36).

No trabalho utilizaremos como parâmetro de estudo as minorias indígenas. Segundo a Fundação Nacional do Índio (Funai), o Brasil está entre os países com maior diversidade étnica e linguística no mundo, pois, apesar da dificuldade de se precisar dados, calcula-se a existência de 220 povos diferentes, sendo mais de 70 isolados e falando pelo menos 180 línguas distintas derivadas de 30 troncos comuns. ${ }^{6}$

Além disso, no censo demográfico do Instituto Brasileiro de Geografia e Estatística (IBGE), de 2010, 817 mil pessoas se declaram indígenas, o que vem a representar $0,42 \%$ do total da população brasileira ${ }^{7}$.

A realidade da existência de diversos povos indígenas em nosso território é inegável ${ }^{8}$. Tal qual é inegável a existência de costumes e modos de vida próprios de cada um desses povos, que deve ser levado em consideração, principalmente considerando que vivemos em uma sociedade globalizada, não apenas em termos econômicos, mas também culturais.
Os Estados Nacionais passaram nos últimos anos não necessariamente por uma transformação de composição, mas sim uma transformação de visão, uma vez que vem sendo observado que a sociedade hegemônica concebida classicamente é uma utopia, pois, de fato o que existe são várias minorias étnicas e soberanas que juntas compõe o Estado tal qual conhecido:

"Assim têm sido as reivindicações coletivas na apreciação dos Estados latino-americanos. Os direitos coletivos são invisíveis, basta ver que as Constituições latino-americanas não apenas omitiam a questão indígena, mas, ao contrário, definiam a nação como baseada em uma única cultura onde todas as pessoas tinham iguais direitos, sem distinção entre etnias ou culturas. A Bolívia, país de maior percentual indígena em toda a América, talvez também o de maior número de constituições, dezenove ao todo, somente em 1994 introduziu direitos indígenas em seu texto" (Souza Filho 2012:85).

Partindo-se de tal premissa, vê-se esvaziada a noção de soberania estatal tal como tradicionalmente pensada, o que traz a necessidade de diálogo entre as plurais formas de estado que existem dentro do País, em várias searas. No caso do presente trabalho, focaremos no respeito e utilização de medicamentos e tratamentos oriundos de conhecimentos tradicionais de comunidades indígenas.

As comunidades indígenas possuem proteção internacional, destacando-se a Convenção no 169 da OIT, que sedimentou no plano mundial a preocupa- 
ção com as comunidades tradicionais e tribais, especificando o cuidado com os indígenas.

$\mathrm{Na}$ verdade, a formação dos Estados Nacionais, principalmente na América do Sul, contou com a participação ativa das comunidades indígenas na luta pela independência. Contudo a única retribuição que tiveram, em sua grande maioria, foi a de serem colocados como cidadãos e terem alguns direitos dispostos expressamente nos textos constitucionais (Souza Filho 2012).

Após a formação dos modernos Estados, ainda aqueles que estabeleceram em seus textos a existência de povos indígenas com garantias e direitos, permaneceu o espírito de formação política una, baseado em uma proposta de acabar com privilégios e criar uma sociedade de iguais, o que, paradoxalmente, resultou na repressão das diferenças étnicas das comunidades indígenas:

"A ideia de que todos os indivíduos estariam convertidos em cidadãos, ou pelo menos de que todo o indivíduo teria direito a se tornar cidadão, traduzia-se na assimilação, absorção ou integração dos povos culturalmente diferenciados" (Souza Filho 2012:63).

Essa integração passou a ser o então espírito do diálogo entre as legislações nacionais, entre as constituições e as comunidades indígenas e foi inclusive o espírito da então Convenção 107 da Organização Internacional do Trabalho, ou seja, a forma de convívio envolvia basicamente hegemonizar toda a sociedade como se fosse apenas uma (Souza Filho 2012). Em outras pala- vras, a comunicação entre os povos se dava através de um diálogo baseado na unicidade e não na compreensão das diferenças através de um discurso de respeito.

Além desse diálogo potencialmente discriminatório, existe a problemática do Estado Nacional que não mais comporta a existência de territórios sem tutela estatal. Destarte, como não poderia existir território indígena com autonomia, há a necessidade de reconhecimento estatal, todavia, tal reconhecimento deveria partir dos dois lados: direitos e deveres dos dois lados, como em todo direito fundamental.

Mesmo com a existência de previsão constitucional e de legislação especial relacionada aos índios, a realidade envolve uma discriminação existente nessa dimensão de assimilação, nessa constante histórica de homogeneização:

"Esta determinação de considerar todos os povos indígenas numa única categoria é uma constante na história das relações dos colonizadores com os povos indígenas tendo gerado o termo único "índio" em contraposição ao nome de cada uma das nações, e a "língua geral", pela qual os missionários queriam que todos os povos os entendessem e se entendessem entre si e principalmente, entendessem a "boa nova" da evangelização" (Souza Filho 2012:73).

\subsection{Constituição política, democracia deliberativa e minorias}

Dentro desse contexto que admite ordens jurídicas distintas e Estado plural e soberano, vem em conjunto ideais 
de constituição efetiva e politicamente construída na diversidade, um texto permeável oriundo de uma concepção de soberania compartilhada com fluxos comunicacionais tanto do Estado como da sociedade civil:

"O substrato social, necessário para
a realização do sistema de direitos,
não é formado pelas forças de uma
sociedade de mercado operante es-
pontaneamente, nem pelas medidas
de um Estado do bem-estar que age
intencionalmente, mas pelos fluxos
comunicacionais e pelas influências
públicas que procedem da socieda-
de civil e da esfera pública política,
os quais são transformados em po-
der comunicativo pelos processos
democráticos" (Habermas 2003:
186)

Essa comunicação ou forma de diálogo é um dos maiores problemas da sociedade moderna, como conciliar e fazer a interação entre as esferas distintas? Como realizar e canalizar as forças e soberanias distintas em um mesmo texto constitucional? Habermas aponta para uma necessária diferenciação da racionalidade das ações sociais, ou seja, formas políticas diferenciadas que juntas concretizam um ideal de soberania e política uno (Gomes 2010).

A utilização da democracia deliberativa seria uma forma de ação social diferenciadora apta a efetivar o diálogo entre ordens distintas:

"Diante do exposto, a democracia, que ainda se coloca no centro da teoria política contemporânea, necessita ser repensada segundo os estudiosos de teoria política de Habermas, a partir da ação efetiva das instituições democráticas e do papel dos cidadãos exercidos no contexto do espaço público e da sociedade civil. Não se trata de um modelo normativo de democracia, centrado no Estado, ou de um modelo representativo (eletivo), que restringe a participação e o engajamento político à atuação de lideranças, mas de um modelo procedimental de democracia que considera como instância de legitimação a "razão" deliberada comunicativamente pela sociedade civil" (Gomes 2010:97)

A ideia de democracia deliberativa é a forma procedimental de garantia da integração social, através de uma participação política mais engajada, que supere o momento do voto, com o uso público da razão, carregando consigo a legitimidade e validade necessária para as decisões políticas:

"A política deliberativa obtém sua força legitimadora da estrutura discursiva de uma formação da opinião e da vontade, a qual preenche sua função social e integradora graças à expectativa de uma qualidade racional de seus resultados. Por isso, o nível discursivo do debate público constitui a variável mais importante" (Habermas 2003:27-28).

A sociedade fechada, que não se comunica, gera uma série de problemas práticos pois, além de uma ausência de legitimidade das ações tomadas em sistemas fechados, há um concreto distanciamento da realidade social, prejudicando a eficácia das eventuais medidas adotadas pelo Estado (Gomes 2010:100).

É necessário resgatar o déficit de legitimação social da política, pois ela não 
se autolegitima apenas pela existência do aparelhamento de Estado, tal qual defendido por Luhmann. Através da política deliberativa baseada em uma constituição política que seja passível de entendimento da diversidade, Habermas traz a possibilidade de um Estado político mais concreto e moralmente correto. (GOMES 2010:100).

\section{A DUPLICAÇÃO DA ESTRADA DE FERRO CARAJÁS: UM EXEMPLO DE DIÁLOGO INEFETIVO}

Como exemplo de como a ausência de interação entre a ordem jurídica tradicional e a ordem jurídica emanada de minorias, no caso, populações indígenas, pode gerar a falta de legitimidade e justiça de decisões administrativas tomadas de maneira legalmente correta, porém politicamente instáveis temos o caso da duplicação da Estrada de Ferro Carajás.

Contextualizado, os indígenas envolvidos na temática são os Gaviões ${ }^{9}$, povo que ocupa o sul e sudeste do Pará às margens do rio Tocantins. Índios da etnia parkategê, tiveram sua formação através da composição de diversas etnias em um só espaço, alguns vindos do alagamento ocasionado pela construção da Usina de Tucuruí, outros trazidos do Maranhão, e que juntos compuseram, durante o governo militar, a depois demarcada Terra Indígena de Mãe Maria.

Importante destacar que a junção desses povos de diferentes origens, apesar da mesma etnia, não se deu de forma espontânea pelos grupos e sim por im- posição de uma ação governamental decorrente do programa Grande Carajás na década de 80 .

Inclusive, há uma série de problemas decorrentes dessa imposição de convivência e confinamento de povos diversos em um mesmo território, causando diversos conflitos e a atual estruturação da Terra Indígena em 12 diferentes aldeias (Fernandes 2010).

A área desses indígenas é diretamente afetada pelo Programa Grande Carajás, que foi criado pelo Decreto 1.813/80, que na época entendeu que aquela rica região de minérios era um espaço homogêneo que poderia ser usado "para fins administrativos, financeiros e fiscais" (Almeida 1994:19).

A própria forma de composição da área das terras indígenas foi pensada e trabalhada sem diálogo com as populações que a integrariam ou que já ali habitavam, demonstrando desde seu início a falta de interação e oitiva desses povos (Santos 2015).

$\mathrm{Na}$ região foram criadas áreas de preservação ambiental diretamente na zona de extração mineral da Serra de Carajás, que em conjunto formam o mosaico de Carajás. Além desse mosaico, houve a demarcação da área indígena dos Gavião: a Reserva Indígena (RI) Mãe Maria, naquela época composta pelos povos parkatêjê, kyikatêjê e akrãntikatêjê e atualmente consignada em 12 diferentes aldeias, todas dentro da mesma reserva (com as problemáticas de junção mencionadas acima).

A Reserva Mãe Maria está distante 20 km de Marabá, no sul do Pará e teve suas terras cortadas pela Ferrovia Ca- 
rajás, nos anos 80 e logo depois pelo linhão de transmissão elétrica da empresa estatal federal de energia elétrica, a Eletronorte.

Os povos indígenas possuem grande e constante interferência no seu território decorrente da construção e uso da Estrada de Ferro Carajás, utilizada para escoamento dos minérios extraídos da Serra de Carajás que são todos os dias levados diretamente, através da estrada, para o porto de São Luís do Maranhão, e depois exportadas para todo o mundo pela empresa, agora privatizada, Vale S.A.

Os impactos decorrentes dessa Estrada de Ferro são compensados através de uma série de políticas assumidas pela empresa Vale S.A e de pagamentos que envolvem convênio firmado com o povo Gavião para concretização de políticas envolvendo segurança, educação, saúde, produção e bem-estar.

Mais recentemente começaram os trabalhos para a duplicação da Estrada de Ferro Carajás em toda sua extensão, o que implica duplicação da área que corta da TI de Mãe Maria, ou seja, mais uma espécie de interferência na área dos indígenas Gavião. O procedimento é acompanhado tanto pela FUNAI em Marabá/PA, quanto pelo Ministério Público Federal.

Em julho de 2016, houve uma série de reuniões da Vale S.A com os indígenas Gavião para debate acerca da duplicação da Estrada de Ferro Carajás dentro da reserva indígena e nas regiões limítrofes da reserva, tais reuniões foram acompanhadas pela FUNAI e tinham como objetivo discutir as necessárias compensações da duplicação dentro da região apenas ${ }^{10}$.

Em setembro de 2016 a FUNAI conferiu para a empresa Vale S.A autorização para funcionamento dos pátios de concentração de trabalhadores para duplicação da Estrada de Ferro Carajás nas áreas limítrofes de início e de final da reserva indígena de Mãe Maria, que segundo os indígenas, já causavam uma série de impactos da reserva. ${ }^{11}$

Os indígenas sustentaram que nas reuniões ocorridas em julho de 2016 não foram explicados para as comunidades os danos que seriam ocasionados pela duplicação de maneira efetiva, não teriam sido ouvidas todas as aldeias da reserva, além do que teria sido ignorado que a duplicação nas fronteiras da TI já seriam causadoras de diversos danos e assim procuraram o Ministério Público Federal para que tutelasse a situação. ${ }^{12}$

Em setembro de 2016 foram expedidas duas recomendações ${ }^{13}$, uma para a empresa Vale S.A e outra para a FUNAI, para que interrompesse imediatamente qualquer autorização e prosseguimento de autorização para duplicação da estrada de ferro Carajás nas fronteiras da reserva indígena de Mãe Maria em razão da ausência de consulta prévia, livre e efetiva com as comunidades, tendo a recomendação sido devidamente acatada pela autarquia e pela Empresa, conforme leitura dos autos do Inquérito Civil competente.

Verifica-se nesse caso que, a decisão administrativa tomada pelo Estado, representado pela FUNAI, em face dos indígenas careceria de legitimidade em 
razão da ausência de diálogo efetivo entre os protagonistas dessa relação: Estado, empresa e comunidades indígenas.

Os elementos do diálogo, entendidos como interlocutores efetivos, mensagem clara e efetiva oitiva de ambos os lados não foram cumpridos, seja em razão da ausência de alguns grupos que compõe a RI de Mãe Maria, seja pela alegação dos indígenas de que não houve explicação clara e suficiente da situação que envolve a duplicação da estrada de ferro, seja pela ausência de disposição das partes em efetivamente dialogar.

$\mathrm{Na}$ ausência de diálogo e de fluxo comunicacional entre os sujeitos envolvidos no caso, tivemos como consequência uma decisão política sem validade e sem legitimidade, se analisada do ponto de vista oriundo da teoria do discurso. Além disso, a ação de autorizar a duplicação da estrada de ferro, no caso, diante da ausência de interação entre as ordens jurídicas tradicional e indígena, fica carente da necessária interculturalidade, demonstrando que nosso sistema jurídico democrático precisa ser repensado através da construção de uma ação comunicativa que preencha essa lacuna política decisória.

\section{CONSIDERAÇÕES FINAIS}

O Estado nacional tal qual concebido implica reconhecimento legal de comunidades e minorias nacionais, caracterizando-se como uma sociedade politicamente plural que emana direito através de ordens jurídicas várias, necessitando-se repensar institutos do campo da ciência política, principalmente o sistema democrático.

A concepção de sociedade una, marcada historicamente pela voz da maioria e pela homogeneização dos direitos humanos acabou por sufocar as diferenças e os traços distintos que compõe a temática dos povos indígenas, corrompendo o ideal de estado multicultural e plural.

O próprio discurso de unicidade traduzido na assimilação e integração dos povos indígenas, antes como realidade legislativa e hoje como discurso potencialmente discriminatório, negligenciou as necessidades das comunidades e, no campo da representatividade, significou e ainda significa a ausência de legitimidade de políticas públicas direcionadas para estas comunidades.

Há uma necessidade de repensar a democracia dentro da ciência política, tanto na busca da interação e representatividade das minorias nacionais que compõe o Estado moderno, quanto pela busca de instrumentos que façam esse papel de preenchimento de lacunas de legitimidade e é nesse ponto que os estudos de Habermas auxiliam na construção de uma base política sólida que justifique o uso de meios alternativos de diálogo, como a consulta prévia por exemplo.

Os fluxos comunicativos e os próprios elementos necessários para o diálogo, tal qual construídos nas teorias de $\mathrm{Ha}$ bermas, são as bases necessárias para a escolha de formas de representatividade bem como de validação de ações políticas assumidas em face das comunidades indígenas. 
A ausência de tais instrumentos acaba segregando e calando as diferenças e necessidades dos índios, que constitucionalmente e internacionalmente possuem o direito de serem ouvidos, o direito de poderem interferir e dialogar sobre as ações que afetem seus modos de vida.

O caso trazido de exemplo de ausência de diálogo demonstra justamente as consequências que sofrem as comunidades pela ausência de representatividade que possuem como minoria. Do ponto de vista tradicional, não há erro na consideração de argumentos validados do ponto de vista da maioria, porém do ponto de vista moral e legitimador, defendido no presente trabalho, a ausência de fluxo comunicacional retira o poder soberano que emana das decisões do Estado que são assumidas sem interação.

Repensando o modelo político tradicional e concebendo a democracia como sistema necessário, porém sujeito a outras formas de interação para completude de sua validade em face das comunidades tradicionais, chegamos à uma sociedade plural politicamente de maneira mais concreta e com respeito aos ideais esposados no texto constitucional e esperados do ponto de vista moral e ético no relacionamento entre Estado e minorias, principalmente as indígenas.

\section{NOTAS}

${ }^{1}$ Preâmbulo (...). Reafirmando que a cultura deve ser considerada como o conjunto dos traços distintivos espirituais e materiais, intelectuais e afetivos que caracteri- zam uma sociedade ou um grupo social e que abrange, além das artes e das letras, os modos de vida, as maneiras de viver juntos, os sistemas de valores, as tradições e as crenças

${ }^{2}$ A globalização já está tendo e continuará a ter um grande impacto no estudo de áreas especializadas do direito. Mas isso está acontecendo de várias maneiras. Algumas tendências claras já são aparentes. Em primeiro lugar, uma maior ênfase está sendo colocada em áreas jurídicas transnacionais já estabelecidas como o direito internacional público, o direito regional, o direito ambiental, o comércio internacional e as finanças (...) como vem sendo observado, desde os anos 90 vem surgindo uma série de reanálises de diversos campos do direito transacionais. (Tradução livre).

${ }^{3}$ Considerando o entendimento até aqui trabalhado de pluralismo jurídico e ordens jurídicas distintas, chega-se à existência de uma soberania em aspectos culturais, onde cada ordem e cada povo terá necessariamente uma cultura ou traços culturais próprios, onde sugere-se uma convivência e não uma absorção ou ignorância acerca dessas diferenciações étnicas.

${ }^{4} \mathrm{O}$ pluralismo jurídico pode ser definido como um conceito que se refere a sistemas jurídicos, redes ou ordens coexistentes no mesmo espaço geográfico. Suas origens remetem aos estudos empíricos das sociedades pós-coloniais dos anos 60 conduzidos por antropólogos legais que mostraram que nas sociedades coloniais e pós-coloniais uma grande quantidade de resoluções sociais e soluções de conflito ocorreram através de normas e processos tradicionais que não foram oficialmente reconhecidos como lei e que às vezes até mesmo estão em conflito com o direito emitido pelo Estado, normalmente denominado como lei e imposta pelas força desse Estado ocidental. Os primórdios do pluralismo jurí- 
dico foram assim sublinhados pela crítica das forças ex-coloniais hegemônicas e por seu desprezo pelo direito indígena e pelas tradições locais. Essa linha de pluralismo jurídico pode ser chamada de um relato pós-colonial do pluralismo jurídico (Tradução livre).

${ }^{5}$ Os cientistas sociais que estudam o pluralismo jurídico, definem que o direito não se limita a ser emitido apelas pelo Estado e suas Instituições jurídicas estabelecidas. Ao contrário, eles insistem que a lei é encontrada e emitida também na ordenação de grupos sociais de todos os tipos. (tradução livre).

6 Brasil. Ministério da Justiça. Fundação Nacional do Índio. Povos indígenas: quem somos. Funai [Internet]. [acesso 10/05/2017]. Disponível: http://www.funai.gov.br/index.html.

${ }^{7}$ Instituto Brasileiro de Geografia e Estatística. Censo 2010. IBGE [Internet]. [acesso 10/05/2017]. Disponível: http:// www.ibge.gov.br/home/.

${ }^{8} \mathrm{O}$ Brasil quando descoberto, em plena expansão européia, já possuia os índios como seus habitantes, possuidores de costumes, tradições e modo de vida. Inicialmente se ignorava a existência de um direito interno das comunidades indígenas e o ímpeto colonizador quase dizimou a cultura desse povo (SOUZA FILHO, 2012).

${ }^{9}$ Ganharam esse nome dado pelo homem branco em razão do tipo de pena que usam em suas flechas e apetrechos (SOUZA FILHO, 2012).

${ }^{10}$ Situação documentada e acompanhada nos autos do Inquérito Civil Público $\mathrm{n}^{\circ}$ 1.23.001.000176/2012-43 da Procuradoria da República em Marabá/PA, cujos autos são de livre acesso.

${ }^{11}$ Alegaram em síntese que viriam para as fronteiras da reserva um número alto de trabalhadores brancos que iriam ter livre acesso à reserva e causariam uma série de inseguranças para as comunidades, com aumento da violência no local, risco para as indígenas, trazida de álcool para as proximidades do povo e etc. Alegaram ainda que as duplicações nas fronteiras da reserva causariam fato consumado e que dali para a duplicação no interior da comunidade, seria uma questão de tempo.

${ }^{12}$ Declaração que deu origem às recomendações expedidas no âmbito do Inquérito Civil Público no 1.23.001.000176/2012-43 da Procuradoria da República em Marabá/ PA, cujos autos são de livre acesso.

${ }^{13}$ http://www.mpf.mp.br/pa/sala-de-imprensa/noticias-pa/ampliacao-da-estrada-de-ferro-carajas-deve-ser-interrompida-para-consulta-a-indigenas-recomenda-mpf

\section{REFERÊNCIAS}

Avbelj, M. The EU and the Many Faces of Legal Pluralism Toward a Coherent or Uniform EU Legal Order?. Disponível em: https://ssrn.com/abstract=1006166. Acesso em 22/05/2017.

Albuquerque, A. A. 2003. Ulian do Lago. Multiculturalismo e o Direito à Autodeterminação dos Povos Indígenas. Dissertação de Mestrado, Centro de Ciências Jurídicas, Universidade Federal de Santa Catarina, Florianópolis, Brasil.

Avritzer, L. 2010. A dinâmica da participação local no Brasil. São Paulo: Cortez.

Bento, I. B., Gomes, L. R., e Jesus, O. F. 2010. Direito e democracia em Habermas: Pressupostos de temas em debate. São Paulo: Xamã.

Brasil. Constituição 1988. Constituição da República Federativa do Brasil: promulgada em 5 de outubro de 1988. Disponível em: <http://www.planalto.gov.br/ ccivil $03 /$ constituicao/constituicao.htm> 
Acesso em: 29 março 2014.

Borrero, C. 1991. A Pluralidade como Direito in Qual Direito? Seminários N. ${ }^{0} 16$. Rio de Janeiro: AJUP/FASE.

Barth, F. 2000. Os grupos étnicos e suas fronteiras in O guru, o iniciador e outras variacões antropológicas. Organizado por T. Lasck, pp. 25-67. Rio de Janeiro: Contracapa Livraria

Casas, Frei B. L. 1995. Obra indigenista. Madrid: Alianza Editorial.

Declaração Universal Sobre A Diversidade Cultural. 11 de setembro de 2001. União das Nações Unidas para a Educação, Cultura e Ciência. Disponível em: www.unesco.org.br. Acessado em: 05/01/2007.

Fernandes, R. F. 2010. Educação Escolar Kyikatêjê: novos caminhos para aprender e ensinar. Dissertação de Mestrado, Programa de Pós-Graduação em Direito, Universidade Federal do Pará, Belém.

Geertz, Clifford. 1989. A interpretação das culturas. Rio de janeiro.

2006. O saber local: novos ensaios em antropologia interpretativa. Petrópolis: Vozes.

Gohn, M. G. 2014. Sociologia dos Movimentos Sociais. São Paulo: Cortez.

Gomes, L. R. 2010. Ação Comunicativa, Democracia e política, in Direito e Democracia em Habermas: Pressupostos e temas em debate. São Paulo: Editora Xamã.

Habermas, J. 1997. Direito e Democracia. Tradução de Flávio B. Siebeneicheler. Rio de Janeiro: Tempo Brasileiro.

1984. Mudança estrutural da es-

fera pública. Tradução de Flávio Kothe. Rio de Janeiro: Tempo Brasileiro.

Jo, H. M. e Sobrino, M. S. 2004. Soberania no Direito Internacional. Brasília [s.n.], jul./set.
Kelsen, H. $A$ democracia. Tradução de Ivone Castilho Benedetti. 2. ed. São Paulo: Martins Fontes.

Kymlicka, W. 1996. Ciudadanía Multicultural. Una teoría liberal de los derechos de las minorias. Traducción de Carme Castells Auleda. Cubierta de Victor Viano. Barcelona: Ediciones Paidós Ibérica S.A.

Laraia, R. B. e Matta, R. 1967. Índios e Castanheiros. São Paulo: Difusão Européia do Livro.

Lorenzo, C. F. G. 2011. Desafios para uma bioética clínica interétnica: reflexões a partir da política nacional de saúde indígena. Revista de Bioética do Conselho Federal de Medicina 19(2): 329-342.

Luhmann, N. 1990. Essays on self-reference. Nova York: Columbia University Press.

Martins, A. C. M. e Mizutani, L. 2011. Direito das Minorias Interpretado: o compromisso democrático do direito brasileiro. Seqüencia: Estudos Jurídicos e Políticos, Florianópolis 32(63):319-352

Melatti, J. C. 1980. Índios do Brasil. São Paulo; Hucitec.

Mendes, G. F., Coelho, I. M., Branco, P. G. G. 2009. Curso de direito constitucional. 4. ed. São Paulo: Saraiva.

Pierré-Caps, S. 2004. O direito das minorias, in Direito das minorias e dos povos autóctones. Organizado por N. Rouland, S. Pierré-Caps, e J. Poummared. Tradução de A. L. Spaltemberg. Brasília: Editora Universidade de Brasília.

Ramos, A. R. 1986. Sociedades Indígenas. São Paulo: Ática.

Rigaux, F. 2003. A lei dos juizes. Tradução de E. Missio. Revisão da Tradução M. E. Galvão. São Paulo: Martins Fontes.

Santos, J. L. R. Povos Indígenas, Direito E Estado: Rompendo Cânones Do Integracionismo Jurídico. Revista Novos Estudos 
Jurídicos - Eletrônica 20(1): 256-283 jan-abr 2015.

Santos, B. de S. 2010. Por uma concepção multicultural de direitos humanos, in Reconhecer para libertar: os caminhos do cosmopolitismo multicultural. 2. ed. Rio de Janeiro: Civilização Brasileira.

Sarmento, D. e Neto, C. P. S. 2014. Direito Constitucional, Teoria, história e métodos de trabalho. $2^{a}$ Edição. Editora Fórum: Belo Horizonte.

Silva, C. T. R. Retórica e abordagem intercultural dos direitos humanos. Disponível em: http://publicadireito.com.br/ artigos $/ ? \operatorname{cod}=\mathrm{b} 6 \mathrm{~d} 6956 \mathrm{cc} 1 \mathrm{fc} 1 \mathrm{e} 8 \mathrm{f}$. Acesso em 20/04/2017.

Silva, P. T. G. 2016. A teoria, o pluralismo jurídico e a interculturalidade crítica: apontamentos desde o Brasil, in Temas em práticas jurídicas e direitos humanos na Psicologia. Campo Grande/MS: UCDB.

Souza Filho, C. F. M. 2012. O Renascer dos Povos para o Direito. Curitiba: Editora Juruá.

Sartori, G. 1965. Teoria Democrática. Rio de Janeiro: Fundo de cultura, 1965. 1994. A teoria da democracia revisitada. São Paulo: Ática. (volume 1). 1994. A teoria da democracia revisitada. São Paulo: Ática. (volume 2).

Schumpeter, J. 1961. Capitalismo, socialismo e democracia. Rio de Janeiro: Fundo de cultura.

Tamanaha, B. Z. 2007. Understanding Legal Pluralism: Past to Present, Local to Global. St. John's Legal Studies Research Paper No. 07-0080. Sydney Law Review 30: 375-411.

Wolkmer, A. C. 1998. Pluralidade Jurídica na América Luso-Hispânica, in Direito e Justiça na América Indigena. Organizado por A. C. Wolkmer. Porto Alegre: Livraria do Advogado.
Yrigoyen Fajardo, R. 2009. "De la tutela a los derechos de libre determinación del desarollo, participación, consulta e consentimiento: fundamentos, balance y retos para su implementación". Amazônica - Revista de Antropologia 1(2):368-405.

Recebido em 10/06/2017

Aprovado em 02/08/2017 